Bull. Mater. Sci., Vol. 35, No. 5, October 2012, pp. 739-744. (C) Indian Academy of Sciences.

\title{
Comparative studies of spray pyrolysis deposited copper sulfide nanostructural thin films on glass and FTO coated glass
}

\author{
MEHDI ADELIFARD*, HOSEIN ESHGHI and MOHAMAD MEHDI BAGHERI MOHAGHEGHI ${ }^{\dagger}$ \\ Department of Physics, Shahrood University of Technology, Shahrood 316-36155, Iran \\ ${ }^{\dagger}$ School of Physics, Damghan University, Damghan, Iran
}

MS received 19 October 2011; revised 5 January 2012

\begin{abstract}
Cu}_{x} \mathrm{~S}$ thin films with different $\mathrm{Cu}$ to $\mathrm{S}$ molar ratios (0.33 and 0.43$)$ have been deposited by spray pyrolysis method on glass and FTO coated glass substrates using an aqueous solution of copper (II) acetate and thiourea at a substrate temperature of $285^{\circ} \mathrm{C}$. The structural, surface morphological, optical and electrical characterizations of the samples were carried out using XRD, FESEM, UV-Vis and PL spectrophotometer and four-probe apparatus, respectively. X-ray diffraction analysis showed that while the layer/glass sample has an individual CuS (covellite) crystalline phase, the layer/FTO sample includes two additional phases of $\mathrm{Cu}_{2} \mathrm{~S}$ (chalcocite) and $\mathrm{Cu}_{1.8} \mathrm{~S}$ (digenite) as well. Optical measurements showed that all these materials have a relatively high absorption coefficient $(\sim 5 x$ $10^{4}-2.3 \times 10^{5} \mathrm{~cm}^{-1}$ ) in the visible region and direct bandgap of the layers was confirmed with the corresponding room temperature PL spectra. With the resistivity measurements at room and higher temperatures $\left(\operatorname{up}^{\text {to }} 100^{\circ} \mathrm{C}\right)$ confirm that all samples are degenerate in nature with high electrical conductivities of $\sim 10^{\mathbf{3}}(\Omega \cdot \mathrm{cm})^{-1}$.
\end{abstract}

Keywords. Semiconductors; nanostructures; optical properties; electrical properties; spray pyrolysis.

\section{Introduction}

In the past few decades, there has been an increasing investigation in semiconducting chalcogenide thin films, which have been due to their wide applications in various fields of science and technology. The study of $\mathrm{Cu}_{x} \mathrm{~S}$ thin films has received much attention due to numerous technological applications in achievement of solar cells, in photochemical conversion of solar energy as solar absorber coating, as selective radiation filters on architectural windows for solar control in the warm climates, as electroconductive coatings deposited on organic polymers, etc (Mattox and Sowel 1974; Gadgil et al 1981; Nair and Nair 1991; Sebastian et al 1994; Lindroos et al 2000; Li et al 2009; Liu and Xue 2009). In the bulk form, $\mathrm{Cu}_{x} \mathrm{~S}$ is known to exist in five stable phases in the room temperature range with chalcocite (orthorhombic $\left.\mathrm{Cu}_{2} \mathrm{~S}\right)$ on the 'copper rich' side and covellite $(\mathrm{CuS})$ on the 'copper deficient' side. Mixed phases are known to exist at intermediate compositions. Depending on the composition, electrical conductivity ( $p$ type) can vary significantly: 0.07 $(\Omega \mathrm{cm})^{-1}$ to $10^{4}(\Omega \mathrm{cm})^{-1}$ as $x$ varied from 2 to 1 . The optical bandgap, $E_{\mathrm{g}}$, of the material is known to vary with $x$; for example, $E_{\mathrm{g} \text {,ind }}=1.05 \mathrm{eV}$ and $E_{\mathrm{g} \text {,dir }}=1.7 \mathrm{eV}$ for $\mathrm{Cu}_{2} \mathrm{~S}$, chalcocite, and $E_{\mathrm{g}, \mathrm{dir}}=1 \cdot 2-3 \mathrm{eV}$ for $x=1$ (covellite) (Nair et al 1998; Isac et al 2007a; Popovici et al 2009).

So far, $\mathrm{Cu}_{x} \mathrm{~S}$ thin films have been prepared by various techniques viz. chemical bath deposition (CBD) (Nair et al 1987, 1988; Nair and Nair 1989), photo chemical deposition

\footnotetext{
*Author for correspondence (adelifard_86@yahoo.com)
}

(Podder et al 2005), metal organic chemical vapour deposition (MOCVD) (Nomura et al 1996) and spray pyrolysis deposition (Madarasz et al 2001; Naumov et al 2002; Nascu and Popescu 2003; Isac et al 2006, 2007b). Spray pyrolysis technique for preparation of thin films from aqueous solution is a promising technique because of its simplicity; by this method a large area of thin film can be deposited without sophisticated equipment.

In this paper, we report on the deposition of $\mathrm{Cu}_{x} \mathrm{~S}$ thin film using the spray pyrolysis technique. The deposition experiment was carried out under various ratios of copper to thiourea using an aqueous solution of copper (II) acetate and thiourea at a substrate temperature of $285^{\circ} \mathrm{C}$ to determine and to compare the structural, optical and electrical properties of the as-deposited films on glass and FTO coated glass.

\section{Experimental}

\subsection{Deposition of $C u_{x} S$ thin film by spray pyrolysis}

An aqueous solution containing $\mathrm{Cu}\left(\mathrm{CH}_{3} \mathrm{COO}\right)_{2} \cdot \mathrm{H}_{2} \mathrm{O}$ (99.9\%, Merck) and thiourea $\left(\mathrm{CS}\left(\mathrm{NH}_{2}\right)_{2}\right)(99.9 \%$, Merck) was prepared using deionized water. The glass and FTO coated glass substrates were ultrasonically cleaned and purged with $\mathrm{N}_{2}$ prior to deposition. The deposition of copper sulfide thin films was carried out with two $\mathrm{Cu}$ to $\mathrm{S}$ molar ratios of $1: 3=0.33$ and $1: 2.28=0.43$ at a substrate temperature of $285^{\circ} \mathrm{C}$ on glass substrate (samples $S 1$ and $S 2$ ) and FTO coated glass (samples $S 3$ and $S 4$ ). Other deposition 
parameters such as spray solution volume, spray deposition rate, nozzle to substrate distance and hot plate rotation speed were maintained at $100 \mathrm{ml}, 7 \mathrm{ml} / \mathrm{min}, 30 \mathrm{~cm}$ and $50 \mathrm{rpm}$, respectively.

\subsection{Characterization of deposited $C u_{x} S$ thin film}

Various characteristics such as structural, morphological, optical and electrical properties of the $\mathrm{Cu}_{x} \mathrm{~S}$ thin films were studied by various techniques. X-ray diffraction (XRD) study was done by a D8 Advance Bruker X-ray diffractometer using $\mathrm{CuK}_{\alpha}(\lambda=1 \cdot 5405 \AA)$ radiation. The morphological analysis was performed by a Hitachi S-4160 field emission scanning electron microscope (FESEM). The optical characterization of the samples was studied by Shimadzu UV1800 spectrophotometer in the spectral range of 300-1100 nm. Thickness of $\mathrm{Cu}_{x} \mathrm{~S}$ films was measured by the Surtronic surface measuring instrument. PL measurement was carried out on an Avaspec 2048 TEC spectrophotometer at room temperature. The electrical properties were measured in the Van der Pauw configuration.

\section{Results and discussion}

\subsection{X-ray diffraction}

The phase and crystallinity of as-deposited $\mathrm{Cu}_{x} \mathrm{~S}$ thin films were analysed by X-ray diffractometer. XRD patterns for samples are shown in figure $1(\mathrm{a}, \mathrm{b})$. The $\mathrm{X}$-ray diffraction pattern of these films revealed that these materials were polycrystalline phases. As it is evident from figure 1, samples $S 1$ and $S 2$ that were deposited on glass substrates, had the covellite phase with hexagonal crystal structure, with (102) as the preferential crystallite direction in $S 1$, but it changed to
(006) in $S 2$ with increasing $\mathrm{Cu} / \mathrm{S}$ molar ratio from 0.33 to 0.43 . The modification in the preferential crystallite direction can be related to the difference in the grain shapes in the layers with various growth parameters (Isac et al 2007b; Boller et al 2009). The data analysis for $\mathrm{Cu}_{x} \mathrm{~S}$ thin films on FTO showed that two additional phases of $\mathrm{Cu}_{2} \mathrm{~S}$ (chalcocite) and $\mathrm{Cu}_{1.8} \mathrm{~S}$ (digenite) present in the samples are in agreement with the results reported by Isac et al (2007b).

According to Scherrer's formula, predominant average crystallite size $(D)$ in polycrystalline samples are determined. The results of these calculations are listed in table 1 . The variations in the crystallite size in these samples affected their optical properties, as described below.

\subsection{Morphological results}

FESEM images of the nanostructural films are shown in figure 2. It can be seen that the films are homogeneous with no visible cracks or holes and average grains related to samples on glass substrate are smaller than samples on FTO substrate. The grains of $\mathrm{CuS}$ samples exhibit spherical shape with diameters lying in the range of 20-40 nm. The correlation of crystalline structure with the surface morphology, depending on the composition and type of substrate, correspond to data analysis of XRD and FESEM shows that the

Table 1. Crystallite size of studied films.

\begin{tabular}{lcll}
\hline Sample & {$[\mathrm{Cu}] /[\mathrm{S}]$} & Substrate & $D(\mathrm{~nm})$ \\
\hline$S 1$ & $0 \cdot 33$ & glass & $26 \cdot 1$ \\
$S 2$ & 0.43 & glass & $25 \cdot 5$ \\
$S 3$ & 0.33 & FTO & $33 \cdot 6$ \\
$S 4$ & 0.43 & FTO & $27 \cdot 4$ \\
\hline
\end{tabular}
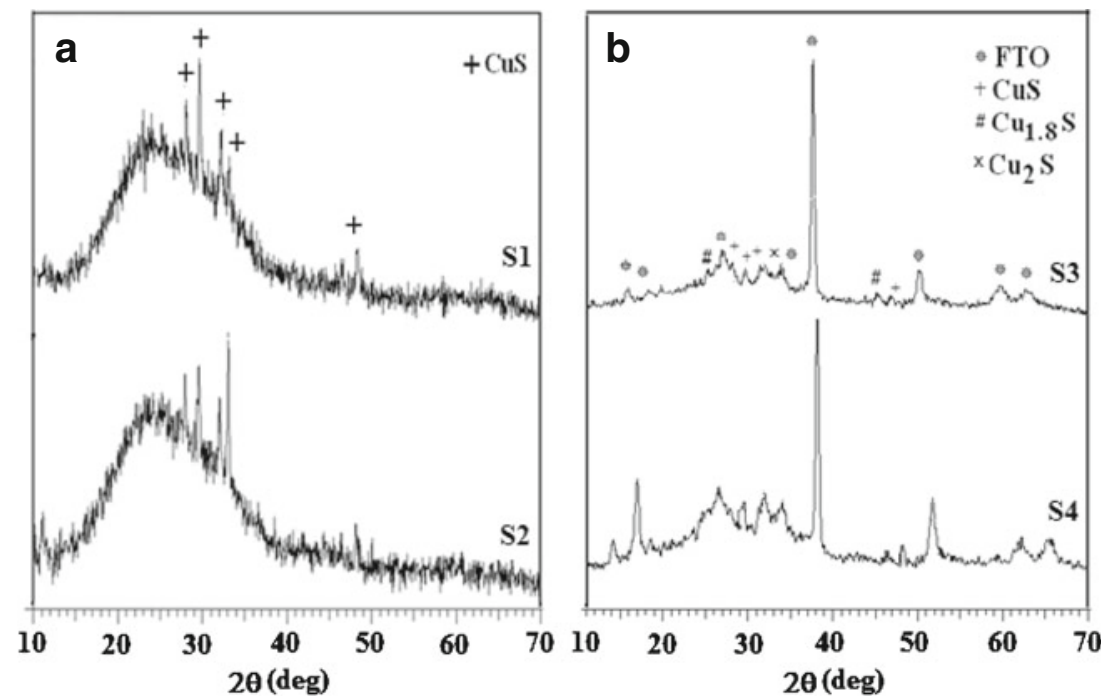

Figure 1. X-ray diffraction patterns of $\mathrm{Cu}_{x} \mathrm{~S}$ thin films deposited at various $[\mathrm{Cu}] /[\mathrm{S}]$ ratios on substrates (a) glass and (b) FTO coated glass. 

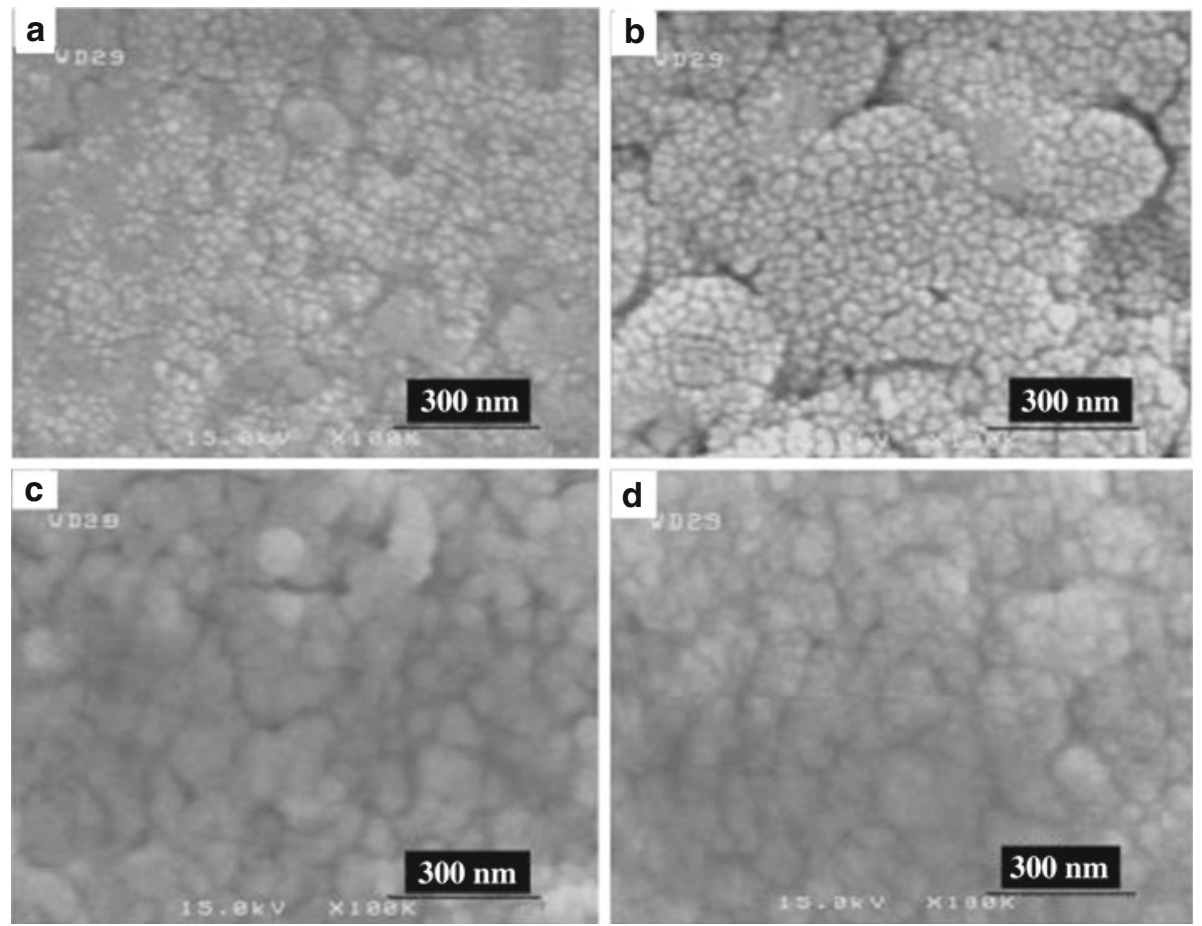

Figure 2. FESEM images of thin films (a) $S 1$, (b) $S 2$, (c) $S 3$ and (d) $S 4$.

deposited samples on FTO substrates $(S 3, S 4)$, include combination of $\mathrm{Cu}_{x} \mathrm{~S}$ phases, which are more homogeneous and denser than the deposited samples with single phases on glass substrates.

\subsection{Optical properties}

Figures 3 (a) and (b) show optical transmittance spectra of copper sulfide thin films. These films have a thickness of $280 \pm 20 \mathrm{~nm}$. As is evident, all samples have a peak transmittances lower than $20 \%$ around $580 \pm 10 \mathrm{~nm}$ and it is notable that the variations of transmission of films are consistent with the variations of crystallite size of the layers (table 1). The greater the crystallite sizes, the higher the optical transmittance of the films, as a result of lower photon scattering by the crystallite boundaries (Manoj et al 2007). It is also notable that a comparison between samples with similar $\mathrm{Sn} / \mathrm{Cu}$ molar ratio shows that the $\mathrm{Cu}$-rich samples ( $S 3$ and $S 4$ samples on FTO coated glass) have a higher transmittance than those with lower copper concentrations ( $S 1$ and $S 2$ samples on glass substrate). This can be as a result of higher conductivity in these samples, as discussed in \$3.4. In addition to transmittance spectra, reflectance of thin layers can also reveal some other physical properties of the samples (figures 4(a) and (b)). According to these results, it is clear that while the studied samples prepared on glass substrate ( $S 1$ and $S 2)$ have a low $(\sim 5-25 \%)$ reflectivity in the visible wavelength range of 400-700 $\mathrm{nm}$, it rises sharply to about $50 \%$ in the near infrared wavelength region (figure 4(a)). These variations in the reflectance spectra accompanied with
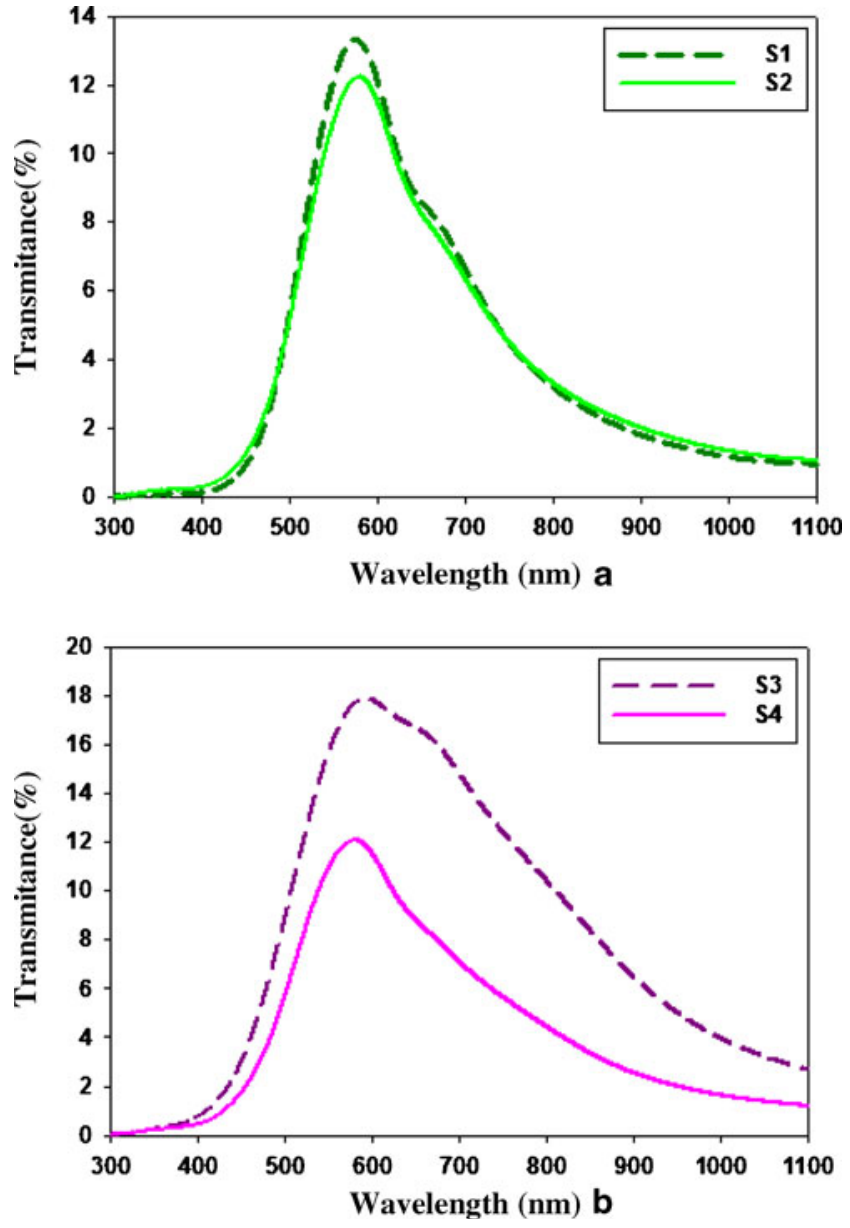

Figure 3. Optical transmittance spectra of $\mathrm{Cu}_{x} \mathrm{~S}$ films. 

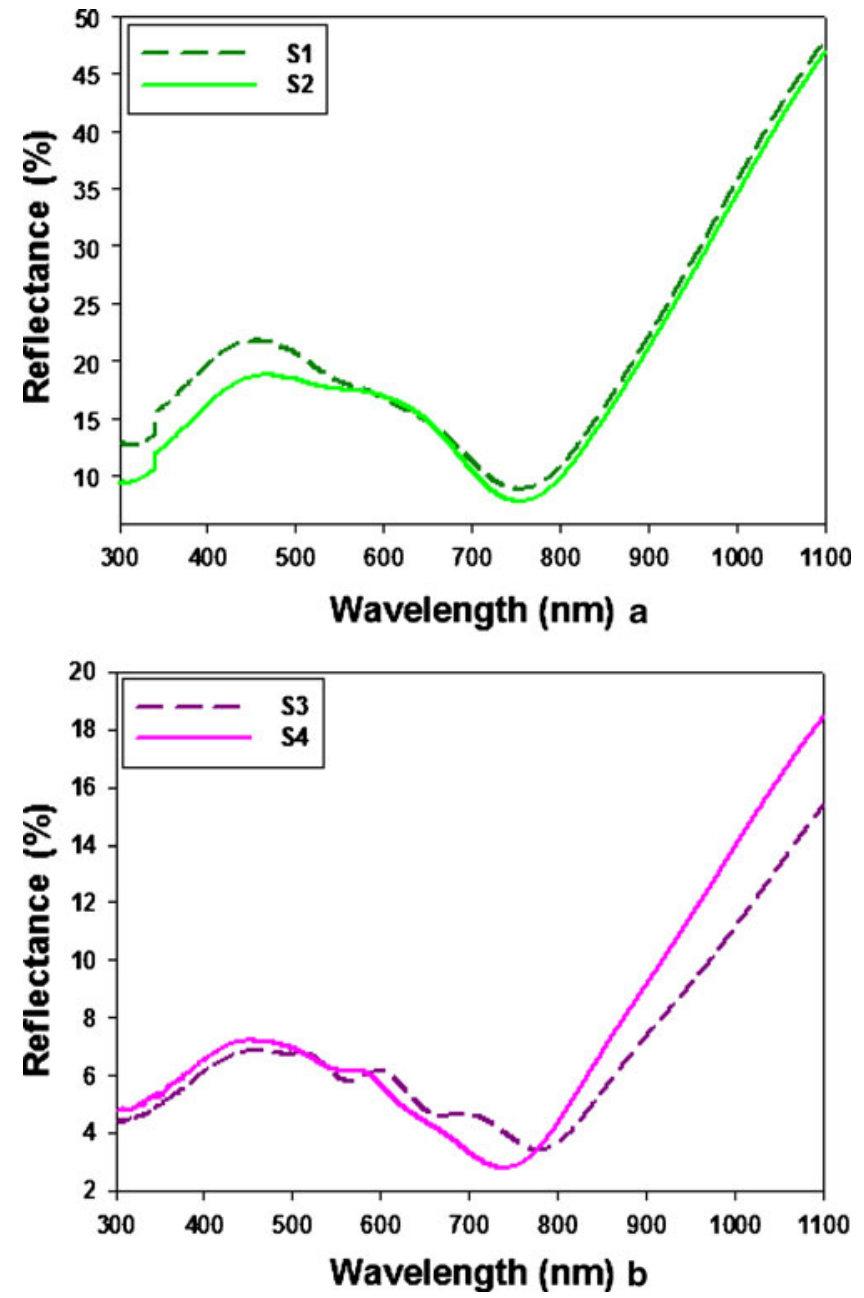

Figure 4. Optical reflectance spectra of studied samples.

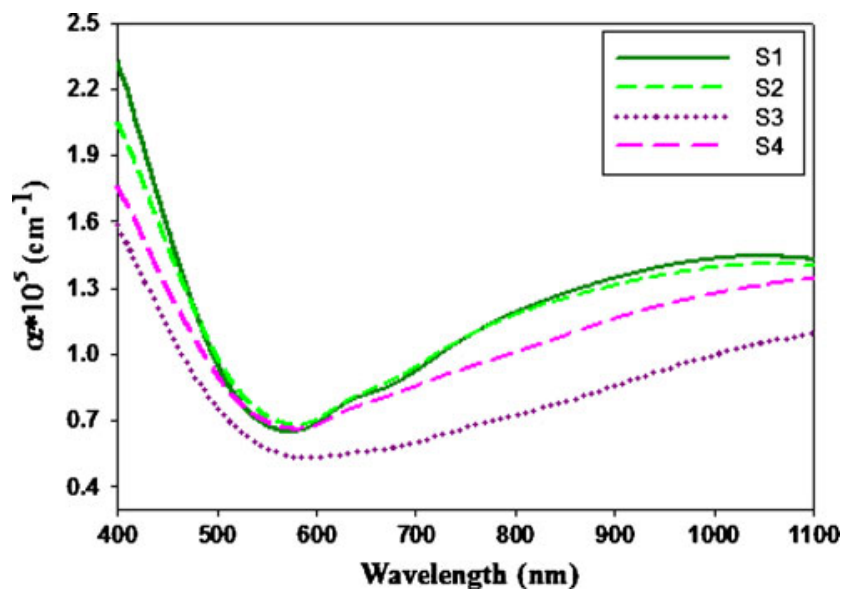

Figure 5. Variations of absorption coefficient vs wavelength in various samples.

relatively low peak transmittances of $\sim 13-19 \%$ in the visible region (figure 3(a)), would be eminently suitable for practical applications in the near-ideal solar control systems (Nair et al 1991). Also it is evident that the samples $S 3$ and $S 4$ have
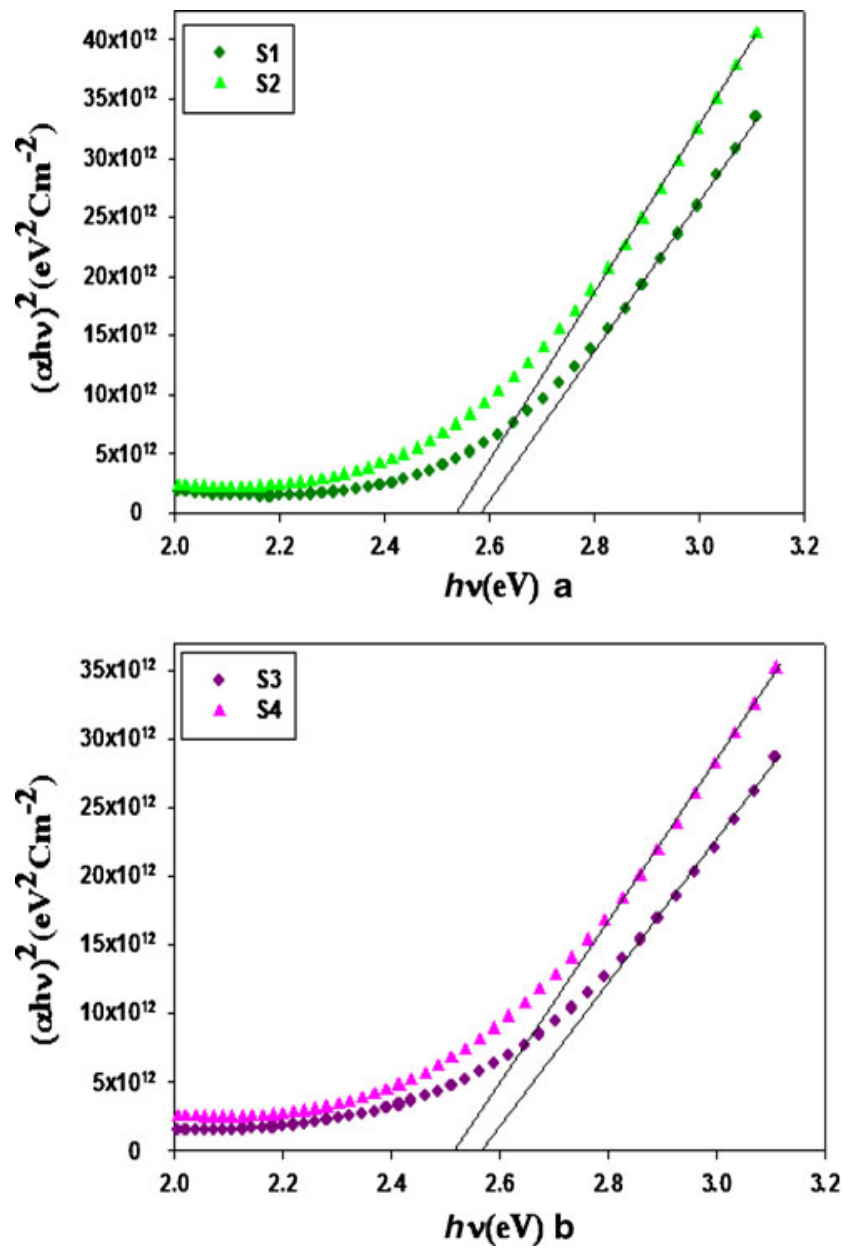

Figure 6. $(\alpha h v)^{2}$ vs $h v$ for films of $\mathrm{Cu}_{x} \mathrm{~S}$ obtained at different $\mathrm{Cu} / \mathrm{S}$ ratios on substrates (a) glass and (b) FTO.

Table 2. Evaluated direct optical bandgaps in $\mathrm{Cu}_{x} \mathrm{~S}$ thin films.

\begin{tabular}{lcc}
\hline Sample $(\mathrm{Cu}: \mathrm{S})$ & Substrate & $E_{\mathrm{g}}(\mathrm{eV})$ \\
\hline$S 1(0.33)$ & glass & $2 \cdot 58$ \\
$S 2(0.43)$ & & $2 \cdot 54$ \\
$S 3(0.33)$ & FTO & $2 \cdot 57$ \\
$S 4(0.43)$ & & $2 \cdot 51$ \\
\hline
\end{tabular}

a lower reflectivity than samples $S 1$ and $S 2$ in both visible and near infrared regions. These results accompanied by low transmittance spectra of these films (figure 3), particularly in the visible region, is a sign of high absorbance in these wavelengths for samples so that these films can be applied in solar cells.

The optical absorption coefficient $(\alpha)$ of $\mathrm{Cu}_{x} \mathrm{~S}$ films has been calculated using the well known expression (Bouaziz et al 2009):

$$
\alpha=1 / d \ln \left((1-R)^{2} / T\right),
$$



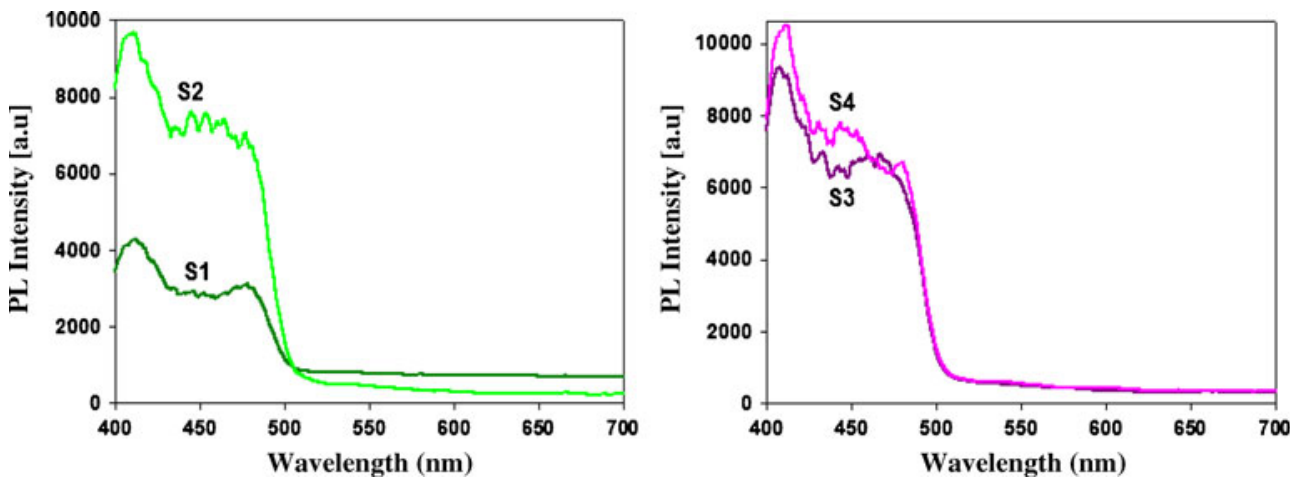

Figure 7. PL spectra of products produced on glass and FTO substrates.

Table 3. Values of sheet resistance and electrical conductivity of studied samples.

\begin{tabular}{lcc}
\hline Sample & $R_{\mathrm{S}}(\Omega / \gamma)$ & $\sigma \times 10^{3}(\Omega . \mathrm{cm})^{-1}$ \\
\hline$S 1$ & 7.46 & 4.7 \\
$S 2$ & $5 \cdot 1$ & 7.6 \\
$S 3$ & 4.83 & 8 \\
$S 4$ & 4.57 & 8.5 \\
\hline
\end{tabular}

where $d$ is the thickness of the layers. It was found that $\alpha$ value for samples are about $10^{5} \mathrm{~cm}^{-1}$ (figure 5). According to these results in all samples there is a nearly sharp absorption variation around $\lambda \approx 500 \mathrm{~nm}$. This behaviour is in agreement with the bandgap calculations given by the plot of $(\alpha h v)^{1 / n}$ vs photon energy, $h v$, for interband transitions:

$$
(\alpha h v)^{2}=A\left(h v-E_{\mathrm{g}}\right),
$$

where $A$ is a constant. Figures 6(a) and (b) show a characteristic plot of the variations in $(\alpha h v)^{2}$ with photon energy, $h v$, near the fundamental edge of all samples. As we can see, for optically measured films we found a linear dependence indicating an allowed direct transition. The values of direct bandgap of these layers are presented in table 2. As seen, the bandgap related to both the films prepared on glass substrates and FTO substrates have decreased as the $\mathrm{Cu} / \mathrm{S}$ ratio increased. This reduction could be attributed to increasing the size of grains or formation of localized states related to the structural defects and variation of the stoichiometry (Rodriguez-Lazcano et al 2009). These results are in good agreement with the corresponding room temperature PL spectra (figure 7). According to these spectra, there is a sharp rise starting at about $412 \mathrm{~nm}$, which is due to the band to band transition and corresponds to room temperature bandgap energy of about $3.0 \mathrm{eV}$ for the deposited nanocrystalline $\mathrm{CuS}$ on the surface. A wide green emission band is proposed to be originated because of the defects in the crystalline structure and a second peak around $480 \mathrm{~nm}$ close to the bulk direct bandgaps of the these materials (table 2), mostly attributed to the radiative recombinations between the conduction band and the copper-vacancy-related acceptor

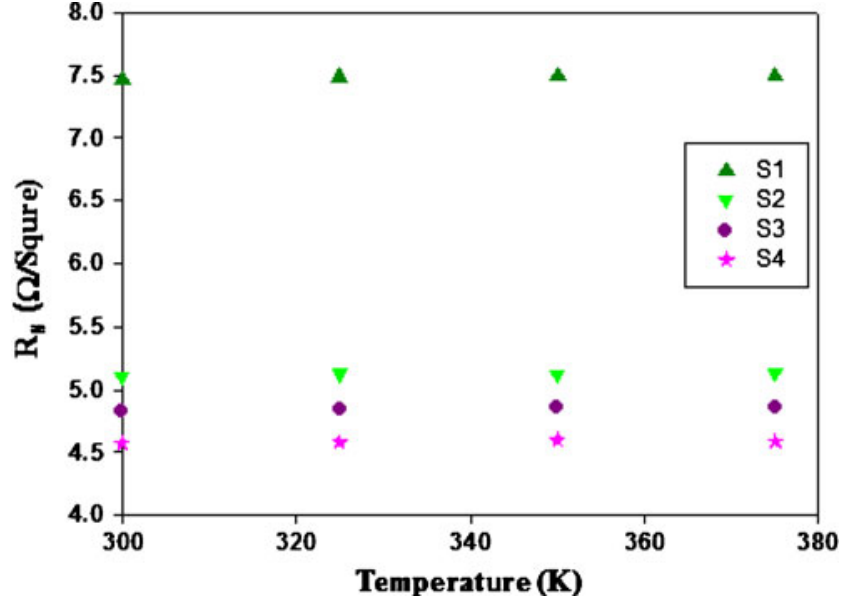

Figure 8. Variation of sheet resistance vs temperature in samples.

levels (Shaomin et al 2005; Thongtem et al 2009). However, the blue shift of this emission peak towards the lower wavelength region is a sign of the quantum confinement effect exerted by the nano-sized $\mathrm{CuS}$ crystals.

\subsection{Electrical properties}

Hall effect measurement was performed for majority carrier identification and all the samples showed a p-type semiconductor nature well-matched with other reports (Isac et al 2007b; Sagade and Sharma 2008; Yuan et al 2008; Boller et al 2009). Table 3 shows results of the sheet resistance and electrical conductivity of the samples. As shown in table 3, all samples present high electrical conductivity of about $10^{3}(\Omega . \mathrm{cm})^{-1}$ and sheet resistance of samples reduce with increase of $\mathrm{Cu} / \mathrm{S}$ ratio. This fact may be related to a higher $\mathrm{Cu}$ content in the samples. The variation of resistivity vs temperature is a reliable method for investigating the level of degeneracy in the studied samples. Figure 8 shows experimental data for all samples, in the temperature range of 300-373 K. It is evident that the sheet resistances in these samples are almost constant in the entire temperature range, confirming the studied layers can be considered as high-level degenerate materials. 


\section{Conclusions}

Copper sulfide nanostructural thin films have been deposited by spray pyrolysis technique with different $\mathrm{Cu} / \mathrm{S}$ molar ratios $(0.33$ and 0.43$)$ on glass and FTO coated glass substrates at a substrate temperature of $285^{\circ} \mathrm{C}$. Structural, morphological, optical and electrical properties were studied. The experimental data reveal that (I) while the layer/glass sample has an individual $\mathrm{CuS}$ (covellite) crystalline phase, the layer/FTO sample includes two additional phases of $\mathrm{Cu}_{2} \mathrm{~S}$ (chalcocite) and $\mathrm{Cu}_{1.8} \mathrm{~S}$ (digenite) as well; (II) samples grown on FTO substrate contain bigger crystallite grain sizes with higher transmittance but lower reflectance in the visible and near infrared regions; (III) the resistivity measurements at room and higher temperatures (up to $100^{\circ} \mathrm{C}$ ) confirm that all samples are degenerate in nature with high electrical conductivities of $\sim 10^{3}(\Omega . \mathrm{cm})^{-1}$ and (IV) data analysis show although all these materials have a relatively high absorption coefficient $\left(\sim 5 \times 10^{4}-2.3 \times 10^{5} \mathrm{~cm}^{-1}\right)$ in the visible range, and the direct bandgap has more reduction in the layers grown on FTO coated glass compared to those grown on glass substrate in agreement with the corresponding room temperature PL spectra.

\section{References}

Boller A, Grossberg M, Asenjo B and Gutierrez M T 2009 Surf. Coat. Technol. 204593

Bouaziz M, Amlouk M and Belgacem S 2009 Thin Solid Films 517 2527

Gadgil S B, Thangaraj R, Lyer J V, Sharma A K, Gupta B K and Agnihotri O P 1981 Sol. Energ. Mater. 5129

Isac L, Duta A, Kriza A, Nanu M, Dumitrescu L and Schoonman J 2006 Proc. 7th int. conf on technology and quality for sustained development TQSD (Bucharest, Romania: AGIR Publishing House) p. 745

Isac L, Duta A, Kriza A, Manolache S and Nanu M 2007a Thin Solid Films $\mathbf{5 1 5} 5755$
Isac L A, Duta A, Kriza A, Enesca I A and Nanu M 2007b J. Phys. Conf. Ser. 61477

Li F, Kong T, Bi W T, Li D C, Li Z and Huang X T 2009 Appl. Surf. Sci. 2556285

Lindroos S, Arnold A and Leskela M 2000 Appl. Surf. Sci. 15875

Liu J and Xue D F 2009 J. Cryst. Growth 311500

Madarasz J, Okuya M and Kaneko S 2001 J. Eur. Ceram. Soc. 21 2113

Manoj P K, Joseph B, Vaidyan V K and Sumangala Devi Amma D 2007 Ceram. Int. 33273

Mattox D M and Sowel R R 1974 J. Vac. Sci. Technol. 11793

Nair M T S and Nair P K 1989 Semicond. Sci. Technol. 4191

Nair P K and Nair M T S 1991 Appl. Phys. 2483

Nair P K, Nair M T S, Campos J and Sansorex L E 1987 Sol. Cells 22211

Nair P K, Campos J and Nair M T S 1988 Semicond. Sci. Technol. 3134

Nair P K, Garcia V M, Fernandez A M, Ruiz H S and Nair M T S 1991 J. Phys. D 24441

Nair M T S, Laura G and Nair P K 1998 Semicond. Sci. Technol. 13 1164

Nascu H and Popescu V 2003 Proc. int. conf. mater. sci. eng. BRAMAT (Brasov Transilvania: Univ. Publishing House). 5 p. 61

Naumov A V, Semenov V N, Lukin A N and Goncharov E G 2002 Inorg. Mater. 38271

Nomura R, Miyawaki K, Toyosaki T and Matsuda H 1996 Chem. Vap. Depos. 217

Podder J, Kobayashi R and Ichimura M 2005 Thin Solid Films 427 71

Popovici I, Isac L and Duta A 2009 Bull. Transilvania. Univ. 251

Rodriguez-Lazcano Y, Martinez H, Calixto-Rodriguez M and Nunez Rodriguez A 2009 Thin Solid Films 5175951

Sagade A A and Sharma R 2008 Sensor. Actuat. B Chem. 133135

Sebastian P J, Gomez-Daza O, Campos J, Banos L and Nair P K 1994 Sol. Energ. Mater. Sol. C. 32159

Shaomin Ou, Qin Xie, Dekun Ma, Jianbo Liang, Xiaokai Hu, Weichao Yu and Yitai Qian 2005 Mater. Chem. Phys. 94460

Thongtem T, Phuruangrat A and Thongtem S 2009 Curr. Appl. Phys. 9195

Yuan K D, Wu J J, Liu M L, Zhang L L, Xu F F, Chen L D and Huang F Q 2008 Appl. Phys. Lett. 93132106 